\title{
Presença pirandelliana na obra de Antonio Tabucchi
}

\author{
Erica Salatini Maffia \\ Universidade Federal da Bahia \\ ericasalatini@gmail.com
}

\begin{abstract}
RESUMO: O presente artigo discute a presença pirandelliana na narrativa do escritor italiano contemporâneo Antonio Tabucchi, partindo do conceito de intertextualidade. Tabucchi é herdeiro da tradição literária italiana, e no que se refere a seus temas, é herdeiro do relativismo pirandelliano, ao mostrar em sua narrativa o reverso das coisas, ao afirmar que determinada coisa que era de um certo modo pode assumir também o seu revés, de acordo com o olhar de quem a observa. Pirandello não só influencia a temática tabucchiana, mas é também um modelo para a construção de seus personagens, assim como uma referência imprescindível para o leitor que quer desvendar os mistérios da escrita tabucchiana.
\end{abstract}

Palavras-chave: Pirandello. Tabucchi. Intertextualidade. Literatura contemporânea.

ABSTRACT: Il presente articolo discute la presenza pirandelliana nella narrativa dello scrittore italiano contemporaneo Antonio Tabucchi, partendo dal concetto di intertestualità. Tabucchi è erede della tradizione letteraria italiana e, per quanto riguarda i suoi temi, è erede del relativismo pirandelliano, perché nei suoi testi fa vedere il rovescio delle cose e afferma che "certe cose che erano in un certo modo" possono anche assumere il loro rovescio, a seconda dello sguardo di chi le osserva. Oltre a influenzare la tematica tabucchiana, Pirandello è anche un modello per la costruzione dei suoi personaggi, così come un riferimento imprescindibile per il lettore che vuole decifrare i misteri della scrittura tabucchiana.

Parole-chiave: Pirandello. Tabucchi. Intertestualità. Letteratura contemporânea.

ABSTRACT: This article discusses the Pirandellian presence in the fiction of the contemporary Italian writer Antonio Tabucchi, starting from the concept of intertextuality. Tabucchi is heir to the Italian literary tradition and, as far as his themes are concerned, he is heir to Pirandellian relativism, because in his texts he shows the reverse of things and states that "certain things that were in a certain way" can also assume their own reverse, depending on the gaze of the observer. In addition to influencing the Tabucchian theme, Pirandello is also a model for the construction of his characters, as well as an essential reference for the reader who wants to decipher the mysteries of Tabucchian writing. 
Keywords: Pirandello. Tabucchi. Intertextuality. Contemporary literature.

\section{Introdução: Tabucchi herdeiro da narrativa pirandelliana}

Antonio Tabucchi, importante representante da literatura contemporânea italiana, trata de temas que são universais, dialoga com várias culturas, em especial com a portuguesa. Reconhecido lusitanista e estudioso do poeta Fernando Pessoa, que em sua obra, torna-se personagem de novelas, contos e de um drama do autor. Mas, apesar da forte ligação com a literatura e a cultura portuguesas, Tabucchi é herdeiro da tradição literária italiana, e no que se refere a seus temas, é herdeiro do relativismo pirandelliano, ao mostrar em sua narrativa o reverso das coisas, ao afirmar que determinada coisa que era de um certo modo pode assumir também o seu revés, de acordo com o olhar de quem a observa.

Pode-se dizer que Pirandello não só influencia a temática tabucchiana, Pirandello é um modelo para a construção do personagem tabucchiano: em Afirma Pereira, romance mais famoso do autor, Tabucchi recebe seu personagem Pereira do mesmo modo que Pirandello recebeu suas seis personagens, em sua obra teatral de maior sucesso. Além disso, Pirandello se torna também personagem ficcional no único drama escrito por Tabucchi, dialogando com Fernando Pessoa. Referência imprescindível para o leitor que quer desvendar os mistérios da escrita tabucchiana, Pirandello é homenageado na literatura de Tabucchi por meio de um fecundo diálogo intertextual.

A filiação da obra de Tabucchi a do grande dramaturgo italiano è inegável, seja no que diz respeito aos temas - alguns temas que Tabucchi empresta de Pirandello, como o conceito de humorismo, o jogo das máscaras, a multiplicação do eu, a busca do outro, levando em consideração os pontos de contato mais evidentes; - seja no uso do relativismo pirandelliano na 
tessitura de sua narrativa; seja no uso dos "jogos cerebrais" que também abundam na obra do escritor contemporâneo.

Pirandello é parte reconhecível e significante da gênese da obra literária tabucchiana e marca presença também em suas convenções técnicas e estruturais. Faz parte da experiência do escritor, como uma fonte vivida: constitui uma experiência individual de uma natureza particular, porque representa uma espécie de intrusão no ser do escritor ou uma modificação (Guillén apud NITRINI, 1997, p. 131).

Como bem nota o crítico Franco Zangrilli:

\begin{abstract}
Pirandello, forse un postmoderno molto tempo prima del postmodernismo, è certamente un padre di Tabucchi, e una presenza continua e informe nella sua opera. (...) In 'Sostiene Pereira', il dialogo immaginario in cui il protagonista si rivolge alla foto della moglie deceduta che ritorna in vita a consolarlo, è plasmato su quello identico che si svolge tra il vecchio Pirandello e la consorte nella novella surrealistica 'Una giornata"' (2015, p. 69).
\end{abstract}

Exemplos como este não faltam na obra de Tabucchi e para mostrar este diálogo entre os dois escritores parece-nos pertinente discutir, em linhas gerais, o conceito de intertextualidade, considerando este uma extensão do conceito de influência. Este último, por sua vez, nos faz notar que a influência pirandelliana é algo que existe na obra de Tabucchi e que não existiria se ele não tivesse lido Pirandello, e que a presença pirandelliana na obra de Tabucchi é tal que nos ajuda a expor porque Tabucchi exprime um pensamento ou sentimento de determinado modo; ou ainda que Pirandello é um dos "antecedentes criativos" do processo de composição tabucchiano. Neste sentido, poderia se falar também de precursor e de tradição literária, já que todo escritor, ao eleger autores ou textos da tradição, tem o privilégio de eleger também o seu passado literário, o seu "cânone", além de eleger também um "eu" que o distingue. Como disse Borges, "todo escritor cria seus precursores. Sua obra modifica nossa concepção de passado, como pode modificar a de futuro". 


\section{A intertextualidade e o sistema de conexões múltiplas do texto literário}

Em seu estudo Literatura Comparada, Sandra Nitrini (1997) mostra como o intertexto refere-se a algo que aparece na obra, que está nela, e não a um amplo processo genético, cujo centro de interesse localizava-se, sobretudo no trânsito, relegando a um segundo plano tanto a origem quanto o resultado. $\mathrm{O}$ conceito de influência tende a individualizar a obra literária, sem nenhuma eficácia. O conceito de intertexto leva em consideração a sociabilidade da escritura literária, cuja individualidade se realiza até certo ponto no cruzamento particular de escrituras prévias:

Todo texto é um intertexto; outros textos estão presentes nele, em níveis
variáveis, sob formas mais ou menos reconhecíveis; os textos da cultura
anterior e os da cultura circundante, todo texto é, enfim, um tecido novo
de citações acabadas. Passam no texto, redistribuídos nele, pedaços de
códigos, fórmulas, modelos rítmicos, fragmentos de linguagens sociais
etc., pois, sempre há linguagens antes do texto e ao redor dele. Assim, a
intertextualidade, condição de qualquer texto, qualquer que ele seja, não
se reduz evidentemente a um problema de fontes ou de influências; o
intertexto é um campo geral de fórmulas anônimas, cuja origem é
raramente localizável, de citações inconscientes ou automáticas feitas
sem aspas (Barthes apud NITRINI, cit., p. 165).

Segundo Nitrini, é importante lembrar que é difícil delimitar o que vem de uma relação direta ou indireta de um autor com outro, o que vem pelo movimento e época literária, o que vem pelos pressupostos culturais comuns e o que é motivado pela situação sócio-econômica e política; portanto, é difícil localizar a intertextualidade implícita para se avaliar o processo de absorção e transformação operado pelo texto receptor e ler a obra, levando em consideração esse fenômeno. Sendo assim, tanto a intertextualidade quanto a influência

constituem conceitos que funcionam bem operacionalmente para se lidar com manifestações explícitas, mas sua instrumentalização para se analisarem ocorrências implícitas dificilmente apresenta resultados satisfatórios, pois estas dependem muito da erudição do leitor. Tanto a 
influência quanto a intertextualidade defrontam-se com problemas ligados à criação literária (NITRINI, cit., p.167).

De qualquer modo, se partirmos do pressuposto de que "todo texto se constrói como mosaico de citações, todo texto é absorção e transformação de um outro texto", assim no lugar da "noção de intersubjetividade, instala-se a da intertextualidade" e a "linguagem poética configura-se, pelo menos, como dupla" e, nessa perspectiva, o texto literário se apresenta sempre como um sistema de "conexões múltiplas" (Kristeva apud NITRINI, cit, p. 162 e ss.).

Devemos ressaltar ainda que a intertextualidade sugere que $\mathrm{O}$ conhecimento é produzido de forma discursiva, e que os intertextos contestam qualquer pretensão em relação às noções humanistas de singularidade e originalidade que o leitor possa desejar atribuir à narrativa, pois atuam no sentido de combater qualquer identidade fixa para o narrador/protagonista ou para o texto e, portanto, qualquer identificação fixa para o leitor.

A partir destas considerações, procuramos apresentar dois textos tabucchianos, dentre tantos outros, que se valem do intertexto pirandelliano para sua composição: Il filo dell'orižonte e Afirma Pereira. Vale lembrar que o próprio autor propõe essas aproximações com a obra pirandelliana em um volume em que trata de sua poética, chamado Autobiografie altrui. Poetiche a posteriori, publicado em 2003.

\section{Intertextos pirandellianos na narrativa de Antonio Tabucchi}

Il filo dell'orizzonte, romance tabucchiano publicado em 1986, ainda não traduzido no Brasil, apresenta não apenas uma temática metafísicoexistencialista de matriz pirandelliana: a busca da própria identidade, mas também um final pirandelliano, constituído a partir do conceito do humorismo. 
Em Il filo dell'orizzonte o protagonista Spino trabalha como auxiliar no necrotério de um hospital, que tenta descobrir a identidade de um cadáver, de um jovem morto em uma ação policial. Trata-se de uma história que parte de um dado da realidade, ao qual Spino tenta dar um sentido, mas quanto mais avança na investigação, mais obscura e cheia de "vazios" ela se torna. O romance termina sem solução, o leitor não consegue saber se o protagonista atinge ou não seu objetivo, se encontra aquilo que busca. O leitor percebe que, no desenrolar da narrativa, para a afirmação da identidade dos personagens, é imprescindível que estes personagens se confrontem com as imagens de si mesmo construídas pelos outros - assim como em muitas narrativas e dramas pirandellianos - Mattia Pascal ressoa em alguns momentos do romance tabucchiano.

Nesse confronto do protagonista, o leitor é lançado em um universo impreciso, em que cada pista oferecida pelo narrador se revela falsa e índice de outro mistério que se configura. $\mathrm{O}$ sentido, desta forma, é sempre incerto, a experiência narrada também é falseada, plena de imaginação, fantasmagoria, lembranças confusas que desnorteiam o leitor em busca de uma "conclusão" para o mistério apresentado. $O$ romance deixa em aberto várias soluções possíveis, sem desapontar ou confundir o leitor, mas fazendo com que intua o “jogo" ficcional, transformando o caráter elusivo do texto em prazer de leitura. O final deixado em aberto se conclui, como em Seis personagens em busca de um autor, com uma risada do personagem Spino e um lançar-se no escuro:

\footnotetext{
Ha aspettato un momento, poi ha ripetuto a voce più alta: 'Sono io, sono venuto'. Solo che in quel momento ha avuto l'assoluta certezza che in quel luogo non c'era nessuno. Suo malgrado ha cominciato a ridere, prima piano, poi più forte. Si è girato e ha guardato l'acqua, a pochi metri di distanza. Poi è avanzato nel nulla (TABUCCHI, 2003, p. 51).
}

Como no drama pirandelliano, que se conclui com a "risada estrídula" da Enteada, e com a escuridão que aos poucos toma conta do palco, o final é 
lançado ao leitor/espectador, que é chamado a construir para si um "final", outra verdade que o autor não soube ou não quis predeterminar (ORVIETO, 2008, p. 90).

Il dramma si chiude con la «stridula risata» della Figliastra. Le ombre dei Personaggi «grandi e spiccate», sotto il fascio di luce d'un riflettore verde, hanno atterrito e volto in fuga il Capocomico. Il Figlio, la Madre, il Padre sono fermi a metà del palcoscenico, «rimanendo lì come forme trasognate». Poco dopo, conclude la didascalia, «calerà la tela». Tutto torna nel buio: i personaggi, gli attori, l'autore invano inseguito da tutti ed egli stesso proteso a inseguire una verità impronunciabile, il puzzle familiare, appena composto e di nuovo dissolto. Pirandello ha messo in scena il proprio autodafé, piantandolo nel cuore della finzione più audace cui spettatori abbiano mai assistito. La colpa, l'abbandono, l'incesto, il rimorso, la punizione fluttuano ancora, incredibilmente leggere, quasi in forma di ectoplasmi, come i personaggi che le incarnano, sulle tavole del palcoscenico. $^{1}$

Notadas as semelhanças, apesar das aparentes diferenças, cabe aqui uma pergunta acerca da originalidade da/na ficção pós-moderna: o que é o original? O que é o absolutamente novo? Dado que na ficção contemporânea este conceito parece não existir ou não ser mais possível, talvez seja pertinente falar em termos de "releitura", no sentido em que o autor, na contemporaneidade, frequentemente propõe uma nova leitura para um "velho" final, deixando entrever assim o que seria a sua "marca de originalidade".

O romance Afirma Pereira é outro dos textos tabucchianos em que o intertexto pirandelliano está presente. Este romance é ambientado em Lisboa, no verão do ano de 1938, pouco antes da invasão da Polônia por Hitler. Pereira é um homem que não vive a história como protagonista, é um jornalista que durante o regime salazarista, escreve obituários em um jornal português. O personagem de Pereira é um homem atormentado, indeciso, uma espécie de anti-herói, que se auto-exclui da história, e que, no final da

1 Giuseppe Leonelli. https://www.pirandelloweb.com/il-teatro-di-pirandello/sei-personaggi-in-cercadautore/ 
narrativa, adquire consciência e cumpre seu gesto de resgate, ao participar ativamente do curso dos acontecimentos. O romance é considerado pelo autor um romance existencialista (FERRARO, 1995), porque existe ali uma crise de consciência. A história oficial é uma espécie de pano de fundo ou de cenário para a ação.

De acordo com Ferraro, Afirma Pereira foi concebido como testemunho de um empenho civil que, tendo amadurecido na consciência do escritor em contato com uma realidade que ele viveu em Portugal nos anos 1960, encontra expressão literária em um romance que transcende os limites históricos e geográficos. O empenho político e civil de Tabucchi é transmitido ao seu personagem, que no momento de sua tomada de consciência, dá-se conta de qual deveria ser o papel do intelectual na sociedade (FERRARO, cit, p. 3 ess.)

Afirma Pereira é uma obra "aberta" e "especular", que tende à fragmentariedade: termina com o protagonista lançando um último olhar ao lençol que cobre o corpo do jovem Monteiro Rossi, assassinado pela polícia política salazarista, enquanto se apressa para sair de cena, sem conhecer seu destino, deixando ao leitor uma série de perguntas em aberto.

É um romance que deve muito à reflexão pirandelliana, seja pela temática que aborda, seja pelo processo de constituição do personagem protagonista, que é feito, como dissemos, aos moldes de Pirandello. O romance também cita implícita e explicitamente Pirandello: no fim do primeiro Capítulo, Pereira cita Pirandello, na rubrica de seu jornal.

Em Um, nenhum e cem mil e O Humorismo, Pirandello mostra seu interesse pela complexidade da personalidade e pela problemática existencial. Pirandello lê Alfred Binet, Les Alterations de la personalité, e o cita em seu ensaio sobre o Humorismo. 
Em Afirma Pereira, um importante personagem do romance, o doutor Cardoso, que acompanha Pereira em sua clínica, também lê este estudioso francês, e explica a Pereira a teoria da confederação das almas. Esta teoria afirma que não existe uma única alma para cada indivíduo. Cada um de nós é "um" desde o nascimento, não forma uma unidade psíquica que depois se fragmenta devido a fatores traumáticos externos, choques que levam à loucura ou à cisão da personalidade. A personalidade é, ao invés, construída de uma confederação de almas que, com o tempo, colocam-se sob o controle de um eu hegemônico. A normalidade mental ou moral não representa uma premissa, mas é um resultado duramente conseguido e virtualmente precário, já que sua manutenção exige um considerável e ininterrupto dispêndio de energia. Governo de coligação: no interior, eus de diversos poderes e influências delegam as próprias prerrogativas ao mais forte e estável entre os vários eus. A sua primazia se conserva até quando não é destruída mediante um ataque frontal ou através de uma lenta erosão, que fazem surgir outras personalidades, que antes eram subalternas. A abdicação do eu hegemônico anterior não dá necessariamente lugar a processos patológicos, à loucura, mas sim a crises saudáveis, a crescimentos de consciências (FERRARO, cit, p. 3 ess.).

Pereira homem melancólico, isolado, depois da morte da mulher vive como se fosse morto. Estabelece um diálogo com a fotografia da mulher, e expressa suas convicções mais íntimas. Sofre de nostalgia do passado, reminiscências da juventude e do matrimônio. Depois do encontro com Marta e Monteiro Rossi, jovens opositores ao regime salazarista, sua atitude reflexiva, ligada ao estudo de obras filosóficas, levam-no a rebelar-se contra o seu fechamento em si mesmo, a tomar consciência do que acontece em torno de si. Inicia, assim, um período de mudanças que, da periferia da sua personalidade, fazem com que o personagem encontre o seu revés, 
arrependendo-se em parte da sua vida de ausência e abrindo-se ao próprio tempo, aos acontecimentos ao seu redor. Pereira se dá conta de que aquilo que acontece na sociedade está ligado à sua existência; percebe que viver do seu passado e da memória desse passado não é suficiente, que deve assumir a responsabilidade diante da injustiça, sobretudo no papel de intelectual e jornalista, e elaborar o próprio luto. Quando se insere na vida dos jovens, sua vida adquire novo sentido. Pereira é um personagem em busca de si mesmo. A partir do segundo capítulo, é como se existissem dois Pereiras: um que continua sua rotina e um outro que, aos poucos, insinua-se nas dobras do primeiro, ocupando os seus interstícios.

Do ponto de vista da criação do personagem Pereira, temos o resgate de um procedimento pirandelliano de composição: como os personagens de Pirandello, Pereira "visita o autor", conta-lhe sua história e pede para se tornar personagem de um romance. Assim como narra Pirandello em suas novelas: Personagens, A tragédia de um personagem e Colóquio com os personagens, novelas que servem de base para a escrita do drama, Seispersonagens em busca de um autor, que por sua vez é base do dialogo intertextual para o romance de Tabucchi.

Em Personagens, novela de 1906, temos um dos primeiros momentos de ficcionalização do autor em sua narrativa, quando Pirandello anuncia o horário de sua audiência para receber os personagens que figurarão em suas futuras novelas:

\footnotetext{
Hoje, audiência.

Recebo das nove às doze, em meu escritório, os senhores personagens de minhas futuras novelas.

Cada tipo!

Não sei por que todos os descontentes da vida, todos os traídos pela sorte, os enganados, os desiludidos e os quase doidos vêm procurar justo a mim. Se os tratasse bem, eu até entenderia. Mas frequentemente eu os trato feito cachorros; e eles sabem que não me contento facilmente, que sou cruelmente curioso, que não me deixo levar por aparências nem me impressiono com conversa fiada. Pelo amor de deus, a alguns peço até provas, testemunhos e documentos. No entanto...
} 


\section{Presença pirandelliana na obra de Antonio Tabucchi \\ Erica Salatini Maffia}

Mas todos têm ou pensam ter (o que dá no mesmo) uma miséria peculiar que deve ser conhecida, e então vêm, petulantes, mendigar a mim voz e vida.

(...) Em seguida, para livrar-me de sua presença e escapar ao assédio mudo e oprimente, me resigno a escutá-los (PIRANDELLO, 2008. p. 346).

É nesta novela que Pirandello apresenta a sua criada Fantasia, que sai furtivamente à procura destes senhores personagens, que comparecem às audiências. $\mathrm{O}$ mesmo procedimento é retomado em $A$ tragédia de um personagem, novela de 1911:

Tenho o velho hábito de, nas manhãs de domingo, conceder audiência aos personagens das minhas futuras novelas. (...) Mas quase sempre me vejo em má companhia. Não sei porquê, mas frequentemente comparecem a essas audiências as pessoas mais infelizes do mundo, acometidas por estranhos males, envolvidas em casos complicadíssimos, com os quais é uma tristeza tratar (PIRANDELLO, 2008. p. 353).

Pirandello adverte que comumente, "nessas audiências, alguns personagens tomam a frente de outros e se impõem com tal petulância e prepotência" que ele se vê obrigado a "despachá-los sem demora".

Em Colóquio com os personagens, novela de 1915, Pirandello, angustiado, às vésperas da guerra, devido à partida de seu filho para a guerra, afixa um cartaz na porta dizendo que as audiências com os personagens estão suspensas, devendo estes dirigirem-se a outros escritores.

Na manhã anterior, eu havia entrado numa áspera discussão com um dos
mais petulantes, que havia cerca de um ano grudara em minhas costas
para que eu extraísse dele e de suas aventuras assunto para um romance
que seria - na sua opinião - uma obra-prima (PIRANDELLO, 2008. p.
360).

Mas este personagem, justamente porque personagem, explica que "na condição de personagem, ou seja, de criatura encerrada em sua realidade ideal, alheia as transitórias contingências do tempo", "não tinha a obrigação de saber em que horrenda e miserável convulsão a Europa se achava naqueles dias".

Nestas novelas, temos a ficcionalização do processo de escrita de Pirandello, que por sua vez, é retomado no Prefácio ao drama Seis personagens; 
texto publicado pela primeira vez em janeiro de 1925, com o título: Come e perché ho scritto $i$ "Sei personaggi", e depois incorporado nas edições posteriores da obra dramática pirandelliana.

Tabucchi retoma esse procedimento pirandelliano em seu Prefácio a Afirma Pereira: após o velório de um jornalista português, crítico do salazarismo, exilado em Paris, dado aparentemente realístico, o autor teria recebido a visita do personagem, que teria lhe pedido para ser narrado sob a forma de um romance.

O Doutor Pereira visitou-me pela primeira vez numa noite de setembro de 1992. Naquela época, ele ainda não se chamava Pereira, ainda não tinha traços definidos, era algo vago, fugidio e indistinto, mas já tinha vontade de ser protagonista de um livro. Era apenas um personagem à procura de um autor. Não sei por que escolheu logo a mim para ser contado.

Em setembro, como dizia, Pereira, por sua vez, veio me visitar. Na hora não soube o que lhe dizer, e, no entanto, compreendi confusamente que aquele vago semblante que se apresentava com o aspecto de um personagem literário era símbolo e metáfora: de algum modo, era a transposição fantasmática do velho jornalista a quem eu fora levar a última saudação. Senti-me constrangido, mas o recebi com carinho. Naquela noite de setembro, compreendi vagamente que uma alma, que vagava no espaço do éter, precisava de mim para se narrar, para descrever uma escolha, um tormento, uma vida. Naquele privilegiado espaço de tempo que antecede a hora de pegar no sono e que, para mim, é o espaço mais idôneo para receber as visitas dos meus personagens, disse a ele que voltasse novamente, que se abrisse comigo, que me contasse sua história. Ele voltou, e eu logo encontrei um nome para ele: Pereira. (TABUCCHI, 2013. p. 6-7).

\section{Considerações finais}

A ficcionalização do autor na própria obra é mais comum em Pirandello que em Tabucchi. Pirandello, como vimos, coloca-se como personagem em várias de suas novelas, assim como também faz referência a si mesmo em seu teatro e em seus romances. Já a escrita de prefácios que explicam como nasceu uma história ou um personagem, procedimento recorrente na narrativa tabucchiana, não é muito frequente em Pirandello, que dá duas importantes advertências ao leitor, sobre suas obras e personagens mais emblemáticos: as 
seis personagens e Mattia Pascal. Ao ler o prefácio tabucchiano sobre a "Aparição de Pereira", evocamos imediatamente estas duas notas pirandellianas. A aparição de Pereira mistura justamente a crônica jornalística e a visita do personagem aos moldes das audiências pirandellianas.

O modo pirandelliano de "criar" seus personagens, retomado por Tabucchi, é, de acordo com o crítico Leonelli, um modo de reelaborar a idéia barroca da reciprocidade e da quase intercambialidade entre mundo e teatro: ideia pela qual somos contemporaneamente espectador e personagem de nós mesmos, e em uma e na outra função, sempre em busca de autor. A vida é representada como um delírio no qual não fazemos mais que enganar a nós mesmos, porque tudo, o que escrevemos e o que vivemos, é apenas fabula, sonho ou mentira, como a literatura. Pense-se na famosa afirmação de Pirandello, muito conhecida por seus leitores, de acordo com a qual a "vida ou se vive ou se escreve". Viver ou escrever a vida é mais ou menos a mesma coisa, porque a arte é "altrettanto vera, e altrettanto falsa", é tão verdadeira quanto falsa.

Ainda em termos de intertextualidade, este mote pirandelliano aparece retomado em alguns prefácios tabucchianos, tanto quanto a ideia barroca de reciprocidade. No prefácio de Il gioco del rovescio, seu primeiro livro de contos, publicado em 1981, Tabucchi diz que não consegue entender qual é o nexo que une a vida que vivemos e os livros que escrevemos. Dez anos mais tarde, em sua coletânea Anjo Negro, um de seus livros em que o citacionismo e o intertexto são elementos constitutivos de sua escrita ficcional, encontramos de novo o mote pirandelliano: "E enquanto isso nós vivemos, ou escrevemos, o que dá no mesmo, nesta ilusão que nos conduz" (TABUCCHI, 1994).

Nesta releitura/reescrita da obra de Pirandello por Tabucchi, a metáfora para a criação se modifica, deixando de ser uma metáfora de expressão e passando a ser uma metáfora de registro de performance, sendo o 
contexto discursivo do registro do texto, uma rede de "múltiplas escritas, obtidas a partir de muitas culturas e envolvendo-se em reações mútuas de diálogo, paródia e contestação" (Barthes apud HUTCHEON, 1991, p. 107).

É interessante retomar, a propósito, os escritos de Barthes (1977) que contestam a noção de autor original e originante, substituindo-a pela ideia de um "escrevente textual ou produtor que só existe no tempo do texto e de sua leitura”. Diz Barthes que: "o único tempo existente é o da enunciação e todo texto é eternamente escrito aqui e a agora". Barthes considera que o leitor é o ativador desta rede contextual e pressupõe a morte do conceito de artista como fonte única e originante do sentido final e autorizado. Por este motivo, o conceito de obra única e fechada se modifica passando a ser um conceito de "texto" plural e aberto. Para Barthes, o "texto" é "aquele espaço social que não deixa nenhuma linguagem a salvo, não deixa de fora nenhuma linguagem". A ideia de texto como sendo aquilo que enfatiza o processo, o contexto e a situação enunciativa é importante para os discursos pósmodernos. O texto pós-moderno, nesse sentido, é capaz de subverter (mesmo que tenha instalado) a ideologia de originalidade que as sustenta. $\mathrm{O}$ escritor pós-moderno "pensa menos em escrever com originalidade, e mais em reescrever. A imagem para a escrita se modifica, deixando de ser a do registro original e passando a ser a da escritura paralela" (Said apud HUTCHEON, cit. 112).

A narrativa tabucchiana, se considerada pela lógica da intertextualidade pós-moderna, passa a ter sentido apenas se observada como parte de discursos anteriores. O intertexto é a "impossibilidade de viver fora do texto infinito" e a intertextualidade é a condição da textualidade. É nesse sentido que o pós-modernismo indica sua dependência em relação ao uso do cânone, mas revela, ao mesmo tempo, sua rebelião com seu abuso irônico desse mesmo cânone. 
La strategia intertestuale è un atteggiamento postmoderno dal momento che rappresenta una rottura con il concetto lineare e progressivo della storia $i$ cui materiali vengono riusati con ironia. L'intertestualità rappresenta l'idea che tutto è già stato detto, l'unica cosa che si può fare è ripensare e interpretare il già detto, ripetere i modelli del passato in forma 'debole', con "pietas", integrando il già detto nei propri testi, come fa Tabucchi (LAUSTEN, 2005, p. 147).

\section{Referências}

FERRARO, B. "Introduzione a Sostiene Pereira". In: TABUCCHI, A. Sostiene Pereira.Turim: Loescher Editore, 1995.

HUTCHEON, Linda. Poética do pós-modernismo. Trad. Ricardo Cruz. Rio de Janeiro: Imago, 1991.

LAUSTEN, Pia S. L'uomo inquieto: identità e alterità nell'opera di Antonio Tabucchi. Copenhagen: Museum Tusculanum Press, 2005,

LEONELLI, Giuseppe - https://www.pirandelloweb.com/il-teatro-dipirandello/sei-personaggi-in-cerca-dautore/

NITRINI, Sandra. Literatura comparada bistória, teoria e crítica. São Paulo: Edusp, 1997.

ORVIETO, P. “1985-1991. Gli anni del giallo e del suo 'oscuramento”. In: I 'Notturni' di Antonio Tabucchi. Atti di seminario. Firenze, 12-13 maggio 2008. Roma: Bulzoni Editore, 2008.

PIRANDELLO, Luigi. 40 novelas de Luigi Pirandello. Trad. Mauricio Santana Dias. São Paulo: Companhia das Letras, 2008.

TABUCCHI, Antonio. Afirma Pereira. Trad. Roberta Barni. São Paulo: CosacNaify, 2013.

. Anjo negro. Trad. Mário Fondelli. Rio de Janeiro: Rocco, 1994.

"Ma cosa ha da ridere il signor Spino?". In: Autobiografie autrui.

Poetiche a posteriori. Milão: Feltrinelli, 2003.

ZANGRILLI, Franco. Dietro la maschera della scrittura: Antonio Tabucchi. Firenze: Polistampa, 2015. 